\title{
Post-traumatic high-flow priapism: uncommon presentation with endovascular management
}

\author{
Pushpinder Singh Khera, ${ }^{1}$ Pawan Kumar Garg $\mathbb{0}$, ${ }^{1}$ Himanshu Pandey, ${ }^{2}$ \\ Kavish Chaurasia'
}

${ }^{1}$ Diagnostic and Interventional Radiology, All India Institute of Medical Sciences, Jodhpur, India ${ }^{2}$ Urology, All India Institute of Medical Sciences, Jodhpur, India

Correspondence to Dr Pawan Kumar Garg; drgargpawan@gmail.com

Accepted 27 September 2019

Check for updates

(c) BMJ Publishing Group Limited 2019. No commercial re-use. See rights and permissions. Published by BMJ.

\begin{tabular}{l}
\hline To cite: Khera PS, \\
Kumar Garg P, Pandey H, \\
et al. BMJ Case Rep \\
2019;12:e229299. \\
doi:10.1136/bcr-2019- \\
229299 \\
\hline
\end{tabular}

\section{DESCRIPTION}

A 24-year-old young man presented to hospital with a history of persistent penile erection associated with mild pain. He sustained a blunt trauma to the pelvis 3 weeks back following a straddle injury while riding a bicycle with no significant external injury. No urethral bleeding at the time of trauma. He was unable to achieve a loss of erection started from day 3 of injury despite the absence of normal libido. On local physical examination, the penis was erect, there was moderate rigidity and slight tenderness. No induration, swelling or ecchymosis were identified. He was treated outside by conservative treatment in the form of ice pack and local compression.

A transperineal ultrasound of the perineum was performed, which revealed bulky bilateral corpora cavernosa with compressed corpora spongiosum. Dilated blood-filled cystic spaces (figure 1A) are seen in bilateral (right >left) corpora cavernosa suggesting dilated sinusoids. Colour duplex Doppler ultrasound revealed high-velocity monophasic colour flow in large irregular cystic space of the right corpora cavernosa suggesting arterio-cavernosal fistula (figure 1B).

Further contrast enhanced CT angiography of the pelvis was performed which revealed filling of right-sided arterio-cavernosal fistula in arterial phase (figure 2A and B) supplied by right internal pudendal artery. On venous phase gradual filling of bilateral corpora cavernosa seen.

In view of presence of post-traumatic arterio-cavernosal fistula in a young unmarried man with no response to conservative treatment and due to patient apprehension, a combined decision

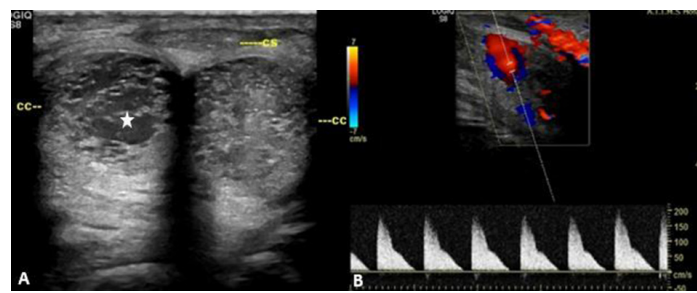

Figure 1 (A) Transperineal ultrasound at the base of the corpora cavernosa showing bulky bilateral corpora cavernosa with compressed corpora spongiosum. Dilated blood-filled cystic spaces (asterisk) are seen in bilateral (right >left) corpora cavernosa suggesting dilated sinusoids. (B) Colour Doppler ultrasound showing highvelocity monophasic colour flow in large irregular cystic space of the right corpora cavernosa suggesting arteriocavernosal fistula.

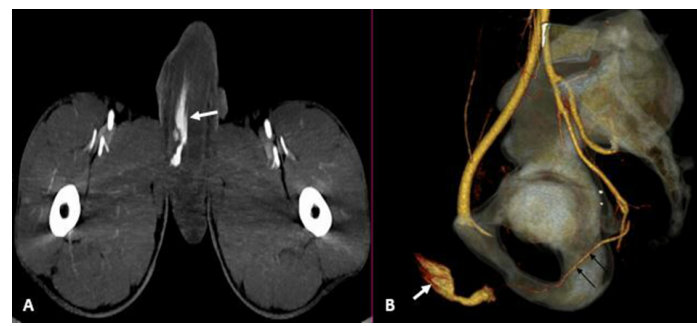

Figure 2 CT angiography. (A) Oblique axial image showing opacification of right cavernous sinus in arterial phase (white arrow). (B) Volume rendered technique oblique view demonstrating fistula supplied by right internal pudendal artery (black arrows).

of embolisation was taken by the interventional radiology and urology teams.

Digital substraction angiography was performed and selective right internal iliac artery angiogram demonstrated arterio-cavernosal fistula supplied by right internal pudendal artery (figure 3A). Superselective angiogram of right internal pudendal artery using 2.7 Fr Progreat microcatheter (Terumo, Japan) close to fistulous site revealed better opacification of fistula by cavernosal branches (figure 3B). Embolisation done using a single $2 \mathrm{~mm}$ x $5 \mathrm{~cm}$ pushable microcoil (0.018" inch diameter, Hilal Microcoils, Cook Bloomington, Indiana, USA). Post-embolisation angiogram (figure 3C) showed obliteration of distal right internal pudendal artery by microcoil (black arrow) with no filling of fistula with maintained flow within rest of the penis. Left internal

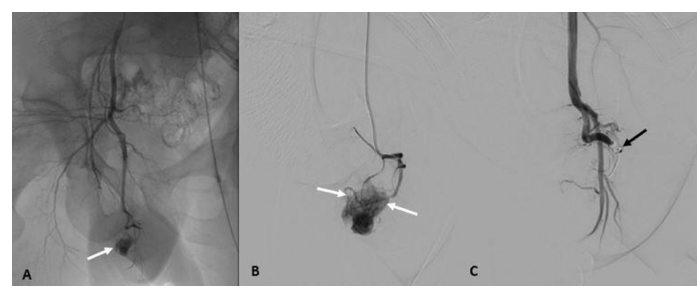

Figure 3 Digital subtraction angiography images: (A) Selective right internal iliac angiogram showing arterio-cavernosal fistula (white arrow) supplied by right internal pudendal artery with prominent venous sac. (B) Superselective cannulation of right internal pudendal artery done close to fistulous site reveal cavernosal branches of right internal pudendal artery (white arrows) supplying fistula. (C) Post-embolisation angiographic run showing obliteration of distal right internal pudendal artery by microcoil (black arrow) with no filling of fistula. 
iliac artery angiogram also taken to make sure no filling of same or other fistula.

Within few hours of procedure patient reported subjective improvement in symptoms and gradual decrease in severity of pain. By third day, his penile erection completely normalised. Patient was also referred for psychological evaluation for possible erectile dysfunction. Patient came for follow-up after 3 months with no residual priapism and at same time no erectile dysfunction.

Non-ischaemic or high-flow priapism because of genitoperineal trauma leading to an arterio-cavernosal communication is relatively uncommon. It should be suspected when the patient presents with mildly painful persistent erection of the penis post-perineal trauma.

Primary management of high-flow priapism consist of conservative treatments such as ice and site-specific compression atleast for initial 2-3 weeks. If conservative treatment fails, then treatment option includes either surgery or endovascular embolisation. Surgery include ligation of internal pudendal artery or its branches. Surgically treated patients have post-treatment potency rates varying from $10 \%$ to $50 \% .^{12}$ This potency rate is less than the patients treated by endovascular means where it is possible to preserve potency in the majority. ${ }^{12}$ Super-selective percutaneous trans-arterial microcatheter embolisation for the treatment of arterial priapism has been cited to be successful

\section{Learning points}

- High-flow priapism should be suspected in post-traumatic patient who presented late with moderate persistent and mildly painful tumescence of the penis.

- Endovascular embolisation is the treatment of choice over surgery since it can selectively obliterate the injured artery with preservation of erectile function in most cases. with a success rates of $80 \%$ as well as in maintaining erectile function in the majority of patients. ${ }^{23}$

First reported embolisation of a high-flow priapism was in 1977 by Wear et al, using an autologous clot. ${ }^{34}$ Since then multiple case report and review articles documented use of different embolic agents including autologous clot, N-butyl-cyanoacrylate, gelfoam and microcoils as a treatment for highflow priapism. ${ }^{34}$ Use of radio-opaque microcoil as an embolic agent after superselective cannulation of microcatheter allows precise and safe focal occlusion and resolution of the traumatic arterio-cavernosal fistula and the pseudoaneurysm. It provides equivalent rate of detumescence in comparison to surgical ligation with better preservation of erectile function.

Contributors PSK has participated sufficiently in the conception of the idea, development of the intellectual content, design and final approval of the manuscript. PKG has participated sufficiently in the development of the intellectual content, design, writing and final approval of the manuscript. HP has participated sufficiently in the conception of the idea, design and writing of the manuscript. KC has participated sufficiently in the conception of the idea, design and writing of the manuscript.

Funding The authors have not declared a specific grant for this research from any funding agency in the public, commercial or not-for-profit sectors.

Competing interests None declared.

Patient consent for publication Obtained.

Provenance and peer review Not commissioned; externally peer reviewed.

\section{ORCID iD}

Pawan Kumar Garg http://orcid.org/0000-0002-5805-1869

\section{REFERENCES}

1 O'Sullivan P, Browne R, McEniff N, et al. Treatment of "high-flow" priapism with superselective transcatheter embolization: a useful alternative to surgery. Cardiovasc Intervent Radiol 2006;29:198-201.

2 Ji MX, He NS, Wang $P$, et al. Use of selective embolization of the bilateral cavernous arteries for posttraumatic arterial priapism. J Urol 1994;151:1641-2.

3 Abujudeh H, Mirsky D. Traumatic high-flow priapism: treatment with super-selective micro-coil embolization. Emerg Radiol 2005;11:372-4.

4 Wear JB, Crummy AB, Munson BO. A new approach to the treatment of priapism. J Urol 1977;117:252-4.

Copyright 2019 BMJ Publishing Group. All rights reserved. For permission to reuse any of this content visit

https://www.bmj.com/company/products-services/rights-and-licensing/permissions/

BMJ Case Report Fellows may re-use this article for personal use and teaching without any further permission.

Become a Fellow of BMJ Case Reports today and you can:

- Submit as many cases as you like

- Enjoy fast sympathetic peer review and rapid publication of accepted articles

- Access all the published articles

Re-use any of the published material for personal use and teaching without further permission

Customer Service

If you have any further queries about your subscription, please contact our customer services team on +44 (0) 2071111105 or via email at support@bmj.com.

Visit casereports.bmj.com for more articles like this and to become a Fellow 